The Journal of

Thoracic and

Cardiovascular

Surgery

Vol 123, No. 4, April 2002

\title{
Surgical substrates of postoperative junctional ectopic tachycardia in congenital heart defects
}

Roger B. B. Mee, MB, ChB, FRACS

See related article on page 624 .
From the Center for Pediatric and Congenital Heart Disease, Cleveland Clinic Foundation, Cleveland, Ohio.

Received for publication Oct 4, 2001; accepted for publication Oct 12, 2001.

Address for reprints: Roger B. B. Mee, MB, $\mathrm{ChB}$, FRACS, Center for Pediatric and Congenital Heart Disease, Cleveland Clinic Foundation, 9500 Euclid Ave, M/41, Cleveland, OH 44195 (E-mail: meer@ ccf.org).

J Thorac Cardiovasc Surg 2002;123:615-6

Copyright (C) 2002 by The American Association for Thoracic Surgery

0022-5223/2002 \$35.00+0 $\mathbf{1 2 / 1 / 1 2 2 5 4 2}$

doi: $10.1067 / \mathrm{mtc} .2002 .122542$

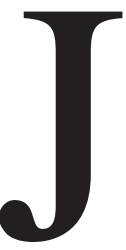

unctional ectopic tachycardia (JET) may severely compromise cardiac output long enough to cause death or multiorgan damage. The hemodynamic impact of JET is probably most severe in those patients who exhibit the most evidence of right, left, or biventricular failure before JET occurs and in those in whom the JET rate most exceeds the heart rate normal for that age group. The heart failure before JET is due to a mosaic of factors: preexisting or new structural lesions inducing volume or pressure loading and preexisting or new myocardial insufficiency (systolic and diastolic dysfunction), with potential exacerbation by high core temperature, inadequate intravascular volume, electrolyte imbalance, and various other factors.

The management of JET is now fairly well established, namely, reduction of core temperature to reduce the JET rate, reduction of unnecessary inotropes, atrial pacing beyond the JET rate, and cautious (2-4 hour) loading with amiodarone followed by continuous infusion, correction of electrolyte and $\mathrm{pH}$ imbalances, and correction of insufficient intravascular volume. Digoxin is probably contraindicated because of its direct action of increasing excitability of all forms of myocardium. Its property of delaying atrioventricular node-bundle conduction is probably irrelevant for managing JET. Theoretically, at least, digoxin may increase the JET rate and delay resolution.

The causes of JET are not clearly understood. Increased excitability of the conducting bundle is probably due to various forms of irritation and minor trauma, coupled with additional unspecified factors. Myocardial muscle stretch has long been considered to increase excitability and electrical instability. Longitudinal stretch of the conducting bundle is an attractive hypothesis in terms of predisposition to JET, as is irritation of the bundle by hemorrhage near the bundle induced by blunt or sharp trauma or by ischemic injury. It must be accepted that some cardiac repairs are more difficult than others and that, for a given congenital diagnosis, there is a range of difficulty in terms of surgical access and thus variation in the amount of retraction used by the assistant. If traction on the bundle is an important contributor to postoperative JET, then it is proper for us to study ways in which traction can be reduced. In tetralogy of Fallot, with some reports of high postoperative JET incidence, it is difficult to impute the actual nature of resection of the right ventricular outflow tract, which is remote from the conducting bundle, with a causal relationship to JET. Gentle handling of the heart with gentle traction is a good rule to start with. The tendency for the assistant to pull harder if he or she sees the surgeon struggling should be resisted, and the surgeon should keep a close eye on this. Most commonly, poor exposure is improved by rearranging the direction of retraction, not by increasing the force. Smaller hearts are more likely to be damaged by a given force of retraction than are larger hearts.

Even with commonsense gentle care of the heart during surgery, JET is unlikely to 
be completely eliminated. Because JET can be so devastating, are we strategizing sufficiently in terms of type of surgical intervention, surgical method, and timing of surgery to minimize the hemodynamic impact of JET?

The incidence of JET varies from center to center for the same lesion, JET is more common after surgery for some lesions than for others, the incidence of JET seems to have some relationship to the timing of surgery for a given lesion, and the hemodynamic impact of JET is more dramatic for some procedures than for others on the same congenital lesion. All these suggest that the incidence and hemodynamic impact of JET may furnish a kind of "bellwether" to grade the overall management strategy in a given center for a given congenital heart lesion.

\section{ON THE MOVE?}

\section{Send us your new address at least six weeks ahead}

Don't miss a single issue of the journal! To ensure prompt service when you change your address, please photocopy and complete the form below.

Please send your change of address notification at least six weeks before your move to ensure continued service. We regret we cannot guarantee replacement of issues missed due to late notification.

\section{JOURNAL TITLE:}

Fill in the title of the journal here.

\section{OLD ADDRESS:}

Affix the address label from a recent issue of the journal here.

\section{NEW ADDRESS:}

Clearly print your new address here.

Name

Address

City/State/ZIP
COPY AND MAIL THIS FORM TO:

Mosby

Subscription Customer Service

6277 Sea Harbor Dr

Orlando, FL 32887
OR FAX TO:

407-363-9661

N/M Mosby
OR PHONE:

800-654-2452

Outside the U.S., call

407-345-4000 